\title{
NGX6 expression improves the sensitivity of tamoxifen-resistant MCF-7 cells through modulation of the Smad signaling pathway
}

\author{
WEN-JING $\mathrm{ZHAO}^{1}$ and $\mathrm{KE} \mathrm{WANG}^{2}$ \\ ${ }^{1}$ Department of Ultrasound, The First Affiliated Hospital of China Medical University, Heping District, Shenyang, \\ Liaoning 110001; ${ }^{2}$ Department of Cardiac Surgery, Shengjing Hospital of China Medical University, \\ Heping District, Shenyang, Liaoning 110004, P.R. China
}

Received January 9, 2013; Accepted March 1, 2013

DOI: $10.3892 /$ ijo.2013.1886

\begin{abstract}
The effects of nasopharyngeal carcinomaassociated gene 6 (NGX6) in breast cancer was studied. We demonstrated that the levels of the NGX6 protein and mRNA were lower in patients with tamoxifen-resistant tumors compared to patients with tamoxifen-sensitive tumors. Tamoxifen was able to decrease proliferation, increase apoptosis and induce $\mathrm{G}_{1}$ arrest in NGX6-expressing TRM-7 cells in vitro. In order to detect the mechanism(s) of tamoxifen action, we first obtain the three-dimensional structure of the NGX6 protein by using Protein Homology/analogY Recognition Engine (PHYRE). Prediction of the docking between the NGX6 protein and tamoxifen was performed using SYBYL-X 1.3. Furthermore, we found that tamoxifen activated Smad2/3, and increased the expression of Smad4 in NGX6-expressing TRM-7 cells as evaluated by western blot analysis. Smad2/3-targeted siRNA was used to confirm the mechanism(s) of tamoxifen action in NGX6-expressing cells. These results indicated that NGX6 may increase the sensitivity of breast cancer cells to tamoxifen.
\end{abstract}

\section{Introduction}

Various cancers associated with the short arm of chromosome 9 for the region contains tumor suppressors (1-5). Nasopharyngeal carcinoma-associated gene 6 (NGX6) localized on chromosome 9p21-22 was originally cloned from nasopharyngeal carcinoma cells (6). The full-length of the NGX6 cDNA is 2134 bp in length and encodes a putative protein of 338 amino acids $(7,8)$. NGX6 expressed at higher levels in normal nasopharyngeal epithelial tissues than cancer tissues (7). Another study showed similar results in colorectal

Correspondence to: Dr Wen-Jing Zhao, Department of Ultrasound, The First Affiliated Hospital of China Medical University, 155 Nanjing Road, Heping District, Shenyang, Liaoning 110001, P.R. China

E-mail: wenj_cmu@163.com

Key words: NGX6, tamoxifen, Smad2/3, apoptosis, breast cancer carcinoma (8). Moreover, NGX6 caused the regression of tumorigenesis and metastasis of colon and nasopharyngeal cancer in vivo $(8,9)$. Accumulating evidence indicates that NGX6 plays a role as suppressor in cancer, however, the effects of NGX6 on breast cancer remain unclear. To better understand the role and mechanism(s) of the NGX6 gene, we upregulated NGX6 expression in breast cancer cells using pCDNA3.1-NGX6 transfection. Then the combined effects of tamoxifen and NGX6 were evaluated in tamoxifen-resistant MCF-7 cells.

Breast cancer is the most frequently diagnosed cancer and the leading cause of cancer death in females worldwide, accounting for $23 \%$ ( 1.38 million) of the total new cancer cases and $14 \%(458,400)$ of the total cancer deaths in 2008 (10). In China, breast cancer is the most frequently diagnosed cancer in women and is the second leading cause of cancerrelated female deaths (11-13). Estrogen action through estrogen receptor (ER)- $\alpha$ is a critical regulator of breast cancer cell proliferation and survival (14). ER-positive breast cancers have low sensitivity to chemotherapy (15). In the past 30 years, tamoxifen has been used for ER-positive breast cancer patients as the primary therapeutic choice. Unfortunately, tamoxifen has no significant efficacy for $>50 \%$ of ER-positive breast cancer patients (16). An adjuvant therapy is required for ER-positive breast cancer treatment.

In the present study, we demonstrate that overexpression of NGX6 promotes the antitumor effects of tamoxifen on tamoxifen-resistant MCF-7 cells, which may be due at least partially to activation of Smad signaling pathway.

\section{Materials and methods}

Breast cancer patient specimens. Specimens were derived from 24 patients with no chemotherapy or radiotherapy before the resection at the Department of Breast Surgery, The First Affiliated Hospital of China Medical University between July 2008 and July 2011. Breast cancer tissue specimens were derived from 12 patients showing tamoxifen resistance (samples 1-12). The control specimens were obtained from other 12 patients who showed no tamoxifen resistance (samples 13-24). Basic patient information is summarized in Table I. All patients approved the use of tumor tissues for clini- 
cal research and China Medical University Ethics Committee approved the research protocols.

Immunohistochemistry (IHC). NGX6 was detected immunohistochemically in $4 \%$ buffered-formalin-fixed, paraffinembedded tissue samples. Thick sections (4- $\mu \mathrm{m}$ thick) were cut and mounted on microscope slides. Endogenous peroxidase activity was blocked by incubating sections in $3 \%$ hydrogen peroxide for $30 \mathrm{~min}$. Antigen retrieval was performed in citrate buffer $(10 \mathrm{mM}, \mathrm{pH} 6.0)$ for $30 \mathrm{~min}$ at $95^{\circ} \mathrm{C}$ in an induction cooker (CH2082, Galanz ${ }^{\circledR}$, Beijing, China). Primary antibody was applied and sections were incubated at $4^{\circ} \mathrm{C}$ overnight. Negative controls were without primary antibodies. Sections were washed with PBS and then incubated with a biotinylated secondary antibody at $37^{\circ} \mathrm{C}$ for $2 \mathrm{~h}$ and then exposed to a streptavidin complex (HRP; Santa Cruz Biotechnology Santa Cruz, CA). Positive reactions were visualized using 3, 3'-diaminobenzidine tetrahydrochloride (DAB; Santa Cruz), followed by counterstaining with hematoxylin (Beyotime, Shanghai, China).

Cell culture. MCF-7 cell lines were obtained from ATCC (Rockville, MD). Cells were maintained at $37^{\circ} \mathrm{C}$ in a $5 \% \mathrm{CO}_{2}$ incubator in RPMI-1640 medium (Sigma-Aldrich, Carlsbad, CA) containing $10 \%$ heat-inactivated FBS and $1 \%$ penicillinstreptomycin. Tamoxifen-resistant MCF-7 (TRM-7) cells were established according to Kim et al (17).

Construction of vectors and transfection. The NGX6 cDNA 2.1-kb fragment that was obtained from the plasmid pBSK including NGX6 (a gift of Wang Yan, China Medical University) was cloned into the EcoRI/XholI sites of the pcDNA3.1 vector. The directional cloning of NGX6 cDNA insert was confirmed by restriction mapping (data not shown). TRM-7 cells were transfected with the pcDNA3.1-NGX6 vector using Lipofectamine ${ }^{\mathrm{TM}} 2000$ (Invitrogen, Carlsbad, CA) according to the manufacturer's instructions. Twentyfour hours post-transfection with pcDNA3.1-NGX6, cells were selected with G418 (450 $\mu \mathrm{g} / \mathrm{ml})$ (Invitrogen) for 10-12 days. Drug-resistant clones were isolated and expanded. The three resulting NGX6-positive cell lines were named T1, T2 and T3.

RNA interference. T1, T2 and T3 cells were transfected at $70 \%$ confluency with $200 \mathrm{nM}$ of Smad2/3-targeted siRNA (Santa Cruz, sc-37238) using Oligofectamine (Invitrogen). Twenty-four hours after transfection, the cells were collected and processed for western blotting and real-time PCR as well as for assessments of cell cycle and apoptosis.

Quantitative real-time PCR and RT-PCR. Total tissue and cellular RNA was isolated using TRIzol reagent (Invitrogen) according to the manufacturer's instructions. First-strand cDNAs were generated in reverse transcriptase reactions containing total RNA, poly(dT) oligonucleotides and SuperScript II reverse transcriptase (Invitrogen). The level of tissular NGX6 mRNA was then subjected to quantitative real-time PCR analysis. NGX6 primers used included 5'-TGACCTGTTCCA AAGAGTCCCTG-3' (forward) and 5'-GCAGCTTCCAGCAC ATATCGACT-3' (reverse). GAPDH primers used included 5'-AGAAGGCTGGGGCTCATTTG-3' (forward) and 5'-AGG
GGCCATCCACAGTCTTC-3' (reverse). Amplification of NGX6 and $G A P D H$ was performed with one cycle at $95^{\circ} \mathrm{C}$ for $10 \mathrm{~min}$ and 40 cycles of $95^{\circ} \mathrm{C}$ for $15 \mathrm{sec}$ and $60^{\circ} \mathrm{C}$ for $60 \mathrm{sec}$. The fold changes between groups were determined by the comparative Ct method (2- $\left.{ }^{-\Delta \Delta C T}\right)(18)$.

PCR amplification of cellular cDNA was performed in 15- $\mu 1$ mixtures. The primers were used as described above. The RT-PCR conditions were: one cycle at $94^{\circ} \mathrm{C}$ for $5 \mathrm{~min}$, followed by 35 cycles of $94^{\circ} \mathrm{C}$ for $45 \mathrm{sec}, 72^{\circ} \mathrm{C}$ for $30 \mathrm{sec}$, $56^{\circ} \mathrm{C}$ for $45 \mathrm{sec}$ and final extension at $72^{\circ} \mathrm{C}$ for $10 \mathrm{~min}$. Finally, products were resolved by $1 \%$ agarose gel electrophoresis and visualized by ethidium bromide staining and a UV imaging system (UVP, Upland, CA).

Cell growth assay. Tamoxifen (T5648) was purchased from Sigma-Aldrich. Cells (1,500 cells/well) including TRM-7, TRM-7 transfected with pcDNA3.1-NGX6 (T1, T2 and T3), T1, T2 and T3 treated with tamoxifen (T1-tam, T2-tam and T3-tam) and T1, T2 and T3 treated with both tamoxifen and siRNA (T1-tam+siRNA, T2-tam+siRNA and T3-tam+siRNA) were plated in 96-well plates and incubated in normal conditions. Then cells were treated with $10 \mu \mathrm{l}$ of MTT solution (5 mg/ml, Sigma). Finally, absorbance was measured at 550-560 nm. MCF-7 cells treated with tamoxifen were used as a control.

TUNEL assay. For apoptosis detection, cells were washed in PBS, fixed, permeabilized and subjected to TUNEL labeling using the in situ cell death detection kit (Keygen, no. KGA702, Nanjing, China) according to the manufacturer's protocol. After counterstaining with DAPI $(1 \mu \mathrm{g} / \mathrm{ml})$, photographic images were taken using an Olympus CX71 fluorescence microscope (Olympus, Tokyo, Japan). TUNEL-positive nuclei were stained green and all other nuclei were stained blue $(19,20)$.

Apoptosis was assessed by the Annexin V/propidium iodide (PI) double staining. In order to calculate the ratio of apoptotic cells quantitatively, cells were harvested and stained with Annexin V/PI according to the manufacturer's instructions (Keygen, no. KGA107). Briefly, cells were collected, washed twice in ice-cold PBS and resuspended in binding buffer at a density of $1 \times 10^{6}$ cells $/ \mathrm{ml}$. The cells were simultaneously incubated with fluorescein-labeled Annexin V and propidium iodide (PI) for $20 \mathrm{~min}$ and flow cytometric (FCM) analysis performed using FACSCalibur (Model FACSC 420, BD Biosciences, Baltimore, MD). Annexin V-FITC generated signals were detected with a FITC signal detector (FL1, $525 \mathrm{~nm}$ ). PI signals were monitored using a detector for phycoerythrin emission (FL2, $575 \mathrm{~nm}$ ). Data were analyzed using CellQuest software (BD Biosciences).

PHYRE database was used to generate a predicted structural model. The protein sequence of NGX6 was obtained from the PubMed (http://www.ncbi.nlm.nih.gov/protein/ NP_001036055.1) and submitted to Protein Homology/ analogY Recognition Engine (PHYRE version 2). Based on homology sequence in PHYRE server, the three-dimensional structure of NGX6 protein was predicted. This method uses structural alignments of homologous proteins of similar three- 
Table I. The antibodies used in the western blot analysis.

\begin{tabular}{llll}
\hline Protein & \multicolumn{1}{c}{ Producer } & Catalog no. & Dilution \\
\hline NGX6 & \multicolumn{1}{c}{ Santa Cruz } & sc-102036 & $1: 200$ \\
& (Santa Cruz, CA, USA) & & \\
P-Smad2/3 & & sc-11769 & $1: 200$ \\
T-Smad2/3 & sc-133098 & $1: 200$ \\
T-Smad4 & sc-7966 & $1: 200$ \\
p21cip1 & sc-6246 & $1: 200$ \\
CyclinD1 & sc-753 & $1: 200$ \\
Caspase-9 & sc-73548 & $1: 200$ \\
Caspase-3 & & sc-7272 & $1: 200$ \\
$\beta$-actin & sc-47778 & $1: 1,000$ \\
\hline
\end{tabular}

dimensional structure in the structural classification of protein databases to obtain a structural equivalence of residues $(21,22)$. Once a three-dimensional structure for NGX6 was predicted using PHYRE database, homology modeling was performed using Modeler (23).

Preparation of the proteins and ligand structures for docking. We applied our approach to the predicted structural model of NGX6. The molecular structure of tamoxifen (CID_2733526) was downloaded from Pubchem Compound (http://www. ncbi.nlm.nih.gov/pccompound). Data were imported into the modeling software SYBYL-X 1.3 (Tripos International, St. Louis, MO). All non-protein components such as water molecules, metal ions and lipids were deleted and hydrogen atoms were added to the protein structures. The interaction of tamoxifen and NGX6 protein was analyzed by SYBYL-X 1.3.

Network data and analysis. The complete set of protein-protein associations for NGX6 was extracted from the downloaded STRING database (http://string-db.org) (24); each association between a pair of proteins has a confidence score (S) ranging from 0.15 to 0.999 that was inferred from the evidence used to establish the association.

Western blotting. Cells $\left(4 \times 10^{5}\right.$ cells $\left./ \mathrm{ml}\right)$ were lysed using lysis buffer $(50 \mathrm{mM}$ Tris- $\mathrm{HCl}, \mathrm{pH}$ 7.4, $150 \mathrm{mM} \mathrm{NaCl}, 1 \%$ Triton $\mathrm{X}-100,0.1 \%$ sodium dodecyl sulfate (SDS), $1 \mathrm{mM}$ ethylenediaminetetraacetic acid (EDTA), $1 \mathrm{mM} \mathrm{Na} \mathrm{VO}_{4}, 1 \mathrm{mM} \mathrm{NaF}$ ). The extracts were incubated on ice for $20 \mathrm{~min}$, centrifuged at $12,000 \mathrm{x} \mathrm{g}$ for $20 \mathrm{~min}$ at $4^{\circ} \mathrm{C}$ and supernatants collected. Protein concentrations were determined using Bradford assay (Bio-Rad, Hercules, CA) and proteins were resolved by $10 \%$ Bis-Tris gel electrophoresis transferred to a nitrocellulose membrane and western blot analysis performed. The cell signaling related proteins probed with primary antibodies are summarized in Table I.

Statistical analysis. All the data were analyzed with the software Statistical Package for Social Sciences (SPSS; V.16.0 for windows; Chicago, IL) and Student's t-test was used. $\mathrm{P}<0.05$ indicated a statistically significant difference.
Table II. Clinicopathologic background factors.

\begin{tabular}{|c|c|c|c|}
\hline $\begin{array}{l}\text { Clinicopathologic } \\
\text { features }\end{array}$ & $\begin{array}{l}\text { Tamoxifen- } \\
\text { sensitive } \\
\text { group }(\%)\end{array}$ & $\begin{array}{l}\text { Tamoxifen- } \\
\text { resistant } \\
\text { group }(\%)\end{array}$ & P-value \\
\hline No. of patients & 12 & 12 & \\
\hline Age (years) & $54 \pm 8$ & $56 \pm 7$ & NS \\
\hline \multicolumn{4}{|l|}{$\begin{array}{l}\text { Hormone receptor } \\
\text { status }\end{array}$} \\
\hline $\mathrm{ER}$ & & & $<0.01$ \\
\hline Positive & $11(91.7)$ & $2(16.7)$ & \\
\hline Negative & 1 (8.3) & $10(83.3)$ & \\
\hline $\mathrm{PR}$ & & & $<0.01$ \\
\hline Positive & $9(75.0)$ & $2(16.7)$ & \\
\hline Negative & $3(25.0)$ & $10(83.3)$ & \\
\hline Stage & & & NS \\
\hline 1 & $5(41.7)$ & $6(50.0)$ & \\
\hline $2 \mathrm{~A}$ & $3(25.0)$ & $3(25.0)$ & \\
\hline $2 \mathrm{~B}$ & $4(33.3)$ & $3(25.0)$ & \\
\hline Grade & & & NS \\
\hline I3 (25.0) & $4(33.3)$ & & \\
\hline II & $6(50.0)$ & $3(25.0)$ & \\
\hline III & $3(25.0)$ & $5(41.7)$ & \\
\hline \multicolumn{4}{|l|}{ Lymph node } \\
\hline metastasis & & & NS \\
\hline Negative & $7(58.3)$ & $6(50.0)$ & \\
\hline Positive & $5(41.7)$ & $6(50.0)$ & \\
\hline Tumor histology & & & NS \\
\hline $\begin{array}{l}\text { Invasive ductal } \\
\text { carcinoma }\end{array}$ & $5(41.7)$ & $6(50.0)$ & \\
\hline $\begin{array}{l}\text { Invasive lobular } \\
\text { carcinoma }\end{array}$ & $3(25.0)$ & $3(25.0)$ & \\
\hline $\begin{array}{l}\text { Medullary } \\
\text { carcinoma }\end{array}$ & $4(33.3)$ & $3(25.0)$ & \\
\hline
\end{tabular}

NS, no significant $(\mathrm{P}>0.05)$.

\section{Results}

The levels of NGX6 protein and mRNA in breast cancer specimens. We classified the 24 patients according to tamoxifen sensitivity. The two groups of patients showed no differences in clinicopathologic background factors except hormone receptor status (Table II). NGX6 protein expression in cancer tissue was significantly lower than in normal tissue in all patients $(\mathrm{P}<0.05)$ (Fig. 1A). However, NGX6 expression was significantly lower in tumor tissues from tamoxifen-resistance patients (samples 1-4) compared to tumor tissues from tamoxifen-sensitive patients (samples 13-16) $(\mathrm{P}<0.05)$ (Fig. 1A). NGX6 transcription was also reduced by real-time PCR analysis. Results showed that 
A
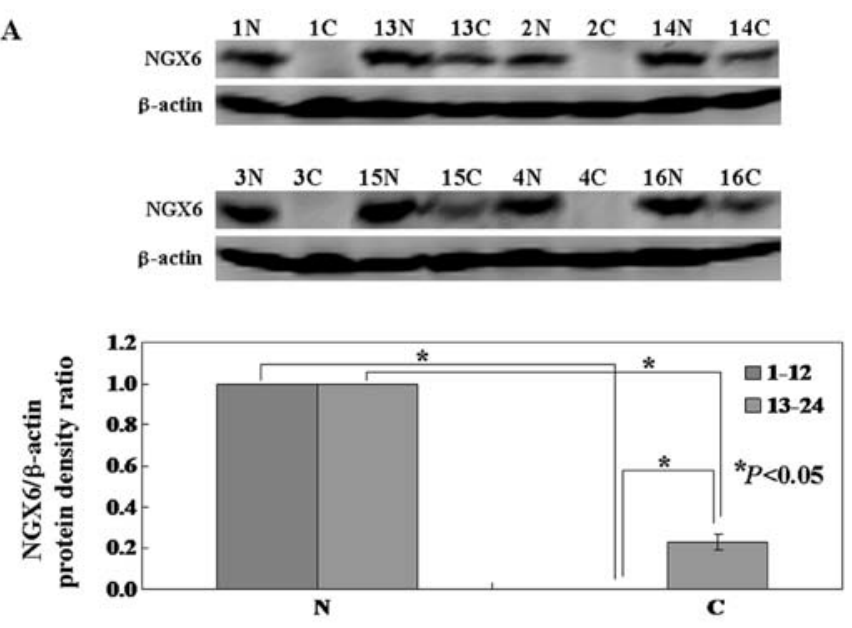

B
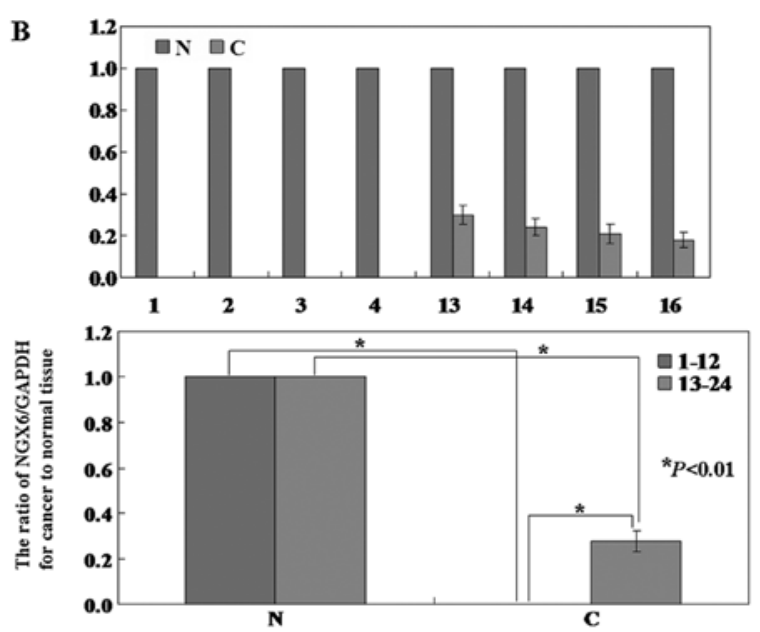

C

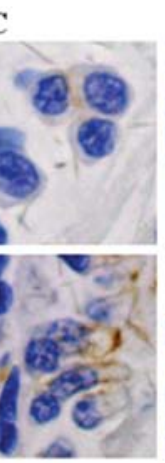

NC

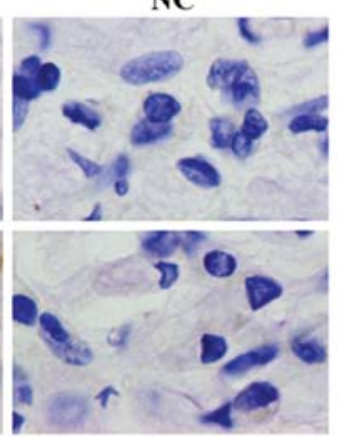

Figure 1. NGX6 protein and mRNA expression in breast cancer tissue specimens. (A) Western blot analysis for NGX6 expression in specimens. NGX6 protein expression level was lower in breast cancer tissue than matched normal tissue $(\mathrm{P}<0.05)$. $\beta$-actin was used as an internal loading control. (B) The level of NGX6 mRNA was lower in breast cancer tissue than matched normal tissue $(\mathrm{P}<0.01)$. GAPDH was used as an internal control. (C) Immunohistochemical staining for NGX6 protein in specimens. NGX6 was stained yellow with granules and localized to the cytoplasm and the cytomembrane. The nuclei were counterstained with hematoxylin. Samples 1-12, tamoxifen-resistant patients; samples 13-24, tamoxifen-sensitive patients. N, normal, C, cancer; NC, negative control.

the levels of NGX6 mRNA and protein were coincident with each other $(\mathrm{P}<0.05)$ (Fig. 1B). The immunohistochemical staining results were consistent with the western blot analysis results (Fig. 1C).

The levels of NGX6 protein and mRNA in breast cancer cells. TRM-7 cells were transfected with pcDNA3.1-NGX6. Stable cell lines were generated and levels of NGX6 protein and mRNA were detected using western blotting and RT-PCR assays. In RT-PCR assays, levels of NGX6 mRNA were lower in TRM-7 cells than in transfected cells (Fig. 2A). To examine the relationship between levels of TRM-7 and transcription of TRM-7, western blotting of TRM-7 was performed. In western blot assays, levels of NGX6 were lower in untransfected TRM-7 cells compared with transfected TRM-7 cells (Fig. 2B).

Growth inhibitory effects of tamoxifen in NGX6-expressing breast cancer cells. We first determined the proper dose of tamoxifen necessary to induce growth inhibition in MCF-7 cells. The $\mathrm{IC}_{50}$ value for tamoxifen was determined by MTT assay $(\mathrm{P}<0.05)$ (Fig. 3A). The proliferation ratio of MCF-7 cells was significantly inhibited and showed a dose-dependent effect $\left(\mathrm{IC}_{50}=5.03 \mu \mathrm{M}\right)$. Growth inhibition was not found in TRM-7 cells after tamoxifen treatment $(\mathrm{P}>0.05)$ (Fig. 3A). T1 cells showed lower viability than TRM-7 cells $(\mathrm{P}<0.05)$

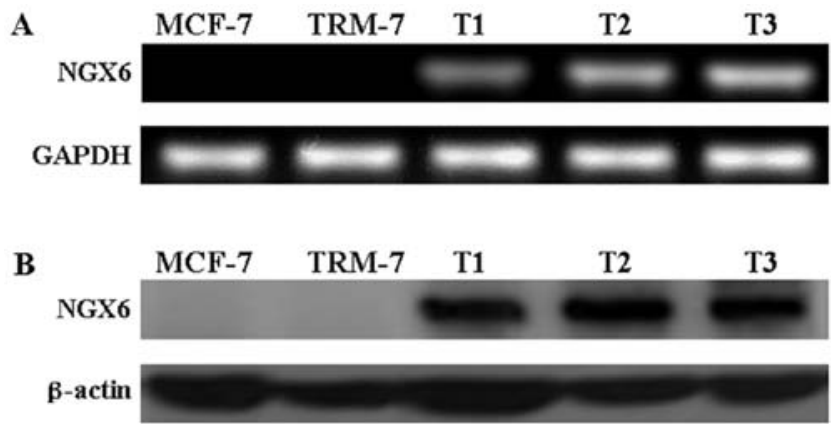

Figure 2. Confirmation of exogenous NGX6 expression in TRM-7 cell clones. RT-PCR (A) and western blot analysis (B) of NGX6 mRNA and protein levels in MCF-7, TRM-7 and TRM-7 cells transfected with pcDNA3.1-NGX6 (T1, $\mathrm{T} 2$ and $\mathrm{T} 3)$, respectively.

(Fig. 3A), however, the proliferation ratio of cells in the T1 group with tamoxifen treatment is significantly lower than cells in the T1 group or TRM-7 group $(\mathrm{P}<0.05)$ (Fig. 3A). Tamoxifen showed no effects on T1 group with Smad2/3targeted siRNA treatment ( $\mathrm{P}>0.05)$ (Fig. 3A).

The ratio of apoptotic cells in each group was determined by TUNEL assay. Results indicate that there was slight apoptosis in $N G X 6$-expressing cells. In contrast, there was a significant increase in the number of apoptotic cells (bright 

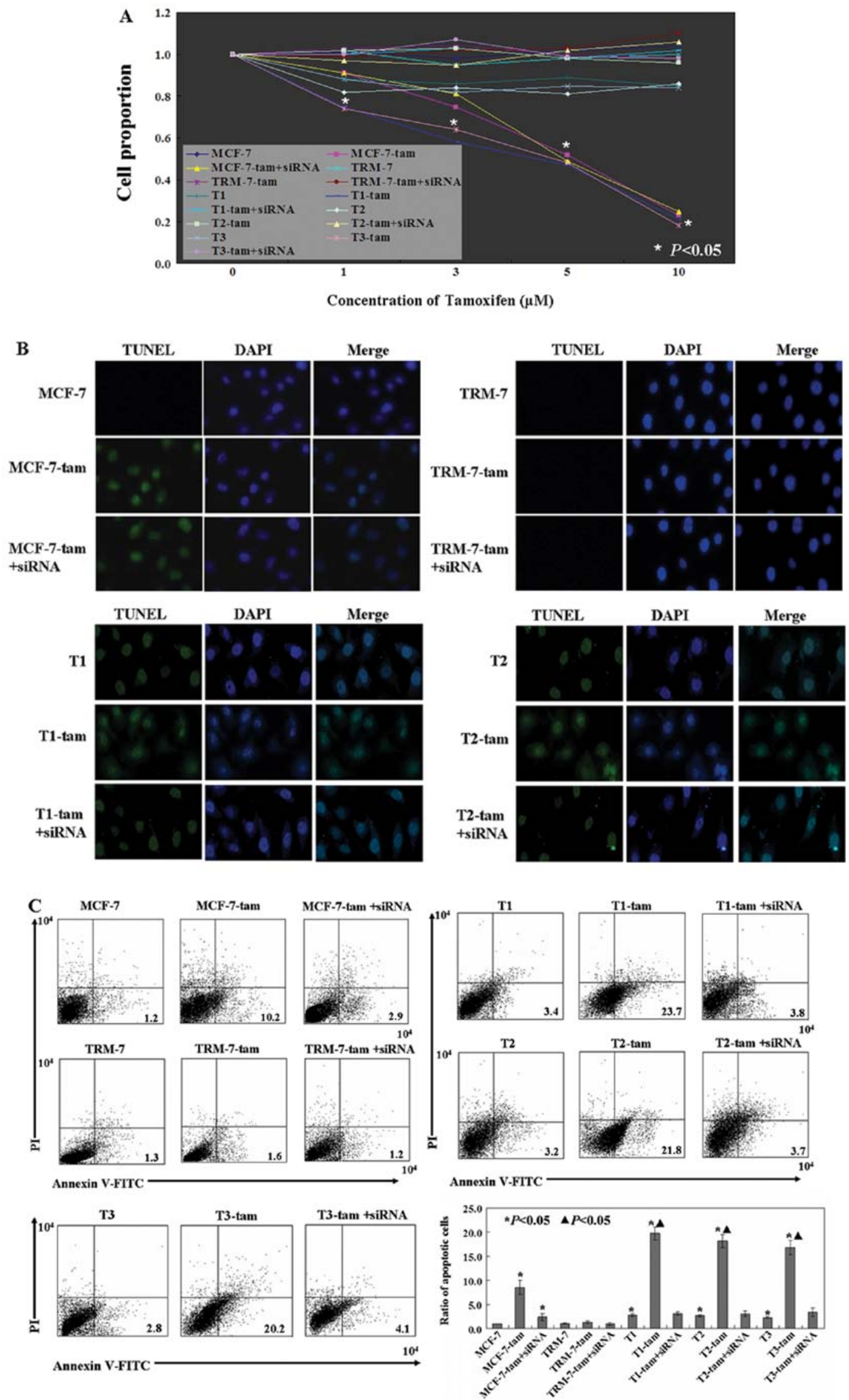

Figure 3. Effects of tamoxifen on NGX6-expressing TRM-7 cells. (A) MTT assay was performed in MCF-7 cells and treated TRM-7 cells and the IC S0 $_{50}$ value for MCF-7 cells was determined and used in the following experiments. (B) Representative TUNEL staining images of cells after treatment. Apoptotic cells with DNA fragmentation were stained positively as green nuclei. (C) Cells were double-stained with Annexin V/PI and FCM analysis performed to determine the percentage of apoptotic cells. (D) Cells were stained with PI to analyze the cell cycle distribution of each group by flow cytometry. Experiments were performed in triplicate and were repeated three times. T1, T2 and T3, three NGX6-expressing clones; T1-tam, T2-tam, T3-tam, T1, T2 and T3 cells treated with tamoxifen; T1-tam+siRNA, T2-tam+siRNA, T3-tam+siRNA: T1, T2 and T3 cells treated with both tamoxifen and Smad2/3-targeted siRNA. 

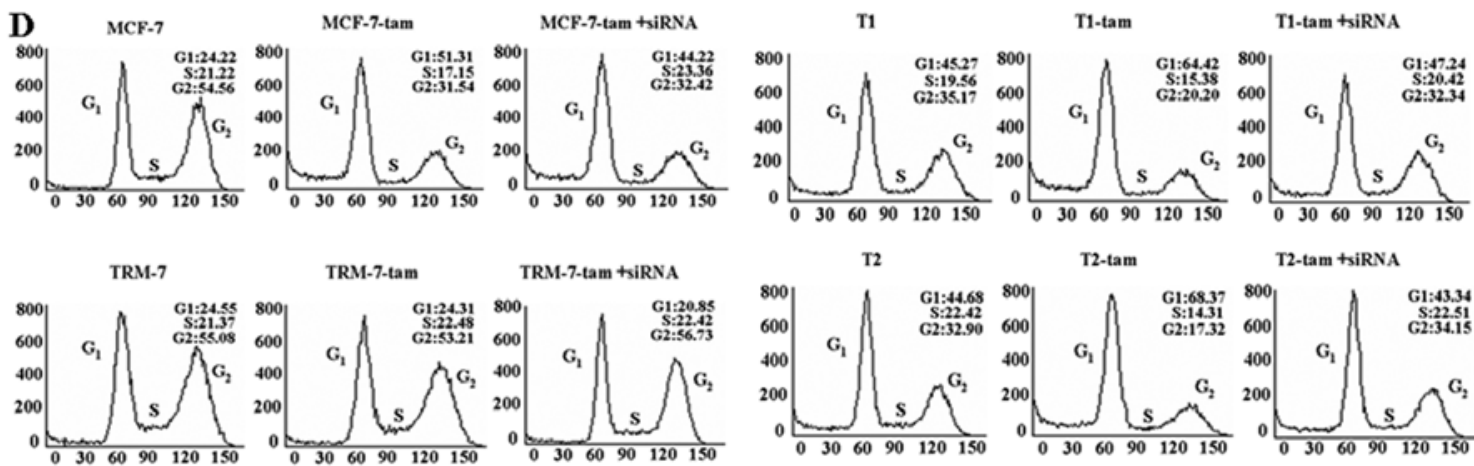

T2-tam tsiRNA
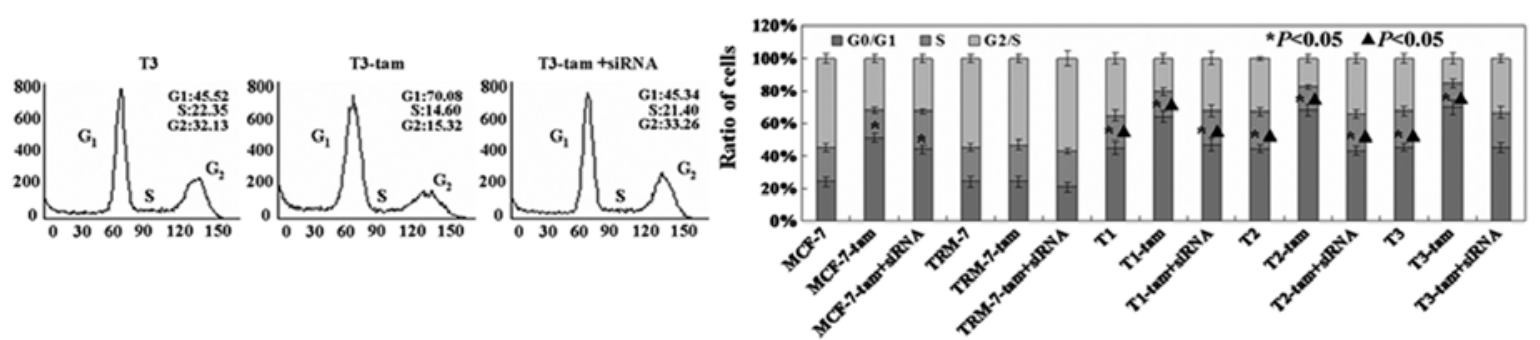

Figure 3. Contiunued. (D) Cells were stained with PI to analyze the cell cycle distribution of each group by flow cytometry. Experiments were performed in triplicate and were repeated three times. T1, T2 and T3, three NGX6-expressing clones; T1-tam, T2-tam, T3-tam, T1, T2 and T3 cells treated with tamoxifen; T1-tam+siRNA, T2-tam+siRNA, T3-tam+siRNA: T1, T2 and T3 cells treated with both tamoxifen and Smad2/3-targeted siRNA.

green) when $N G X 6$-expressing cells underwent tamoxifen treatment (Fig. 3B). The results were quantified by using

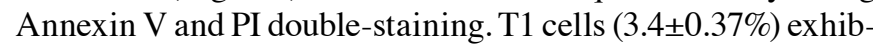
ited increased apoptosis compared to TRM-7 $(1.3 \pm 0.28 \%)$ $(\mathrm{P}<0.05)$ (Fig. 3C). The number of apoptotic cells in the T1-tam group $(23.7 \pm 1.25 \%)$ is significantly higher than that in the T1 group. Furthermore, the apoptotic cells in T1-tamsiRNA group showed no significantly changes compared to T1 group ( $\mathrm{P}>0.05)$ (Fig. 3C).

The effect of NGX6-expression and tamoxifen on the cell cycle of breast cancer cells was determined by PI staining. The percentage of the $\mathrm{T} 1$ cells in $\mathrm{G}_{1}$ phase $(45.27 \%)$ was increased when compared to the TRM-7 $(24.55 \%)$ cells. More increased cells of T1-tam group (64.42\%) in $\mathrm{G}_{1}$ phase were found than that in $\mathrm{T} 1$ group $(\mathrm{P}<0.05)$ (Fig. 3D). No changes were found in T1-tam-siRNA group compared to T1 group $(\mathrm{P}>0.05)$ (Fig. 3D). Results of all above experiments using T2 and T3 clones were comparable to results using the T1 clone (Fig. 3).

The mechanism(s) of tamoxifen in NGX6-expressing breast cancer cells. In addition, we detected the mechanism of NGX6 in breast cancer cells. Firstly, PHYRE analysis predicted reelin [a large glycoprotein secreted from Cajal-Retzius cells of developing cerebral cortex (25)] as a factor with significant structural homology to NGX6 (Fig. 4A). The homology modeling for NGX6 protein was performed using PHYRE server with template that generated with highest similarity percentage (Fig. 4B). Secondly, we found the interaction of NGX6 protein and tamoxifen. As shown in Fig. 4C, the results of the computer modeling showed that tamoxifen was bound to the active sites of NGX6 protein. Lastly, a raw network consisting of the highest scoring interaction partners of NGX6 was arranged by using STRING database (Fig. 4D). Based on the results, we focused on cyclin D1 (CCND1), a regulator of cell cycle, for $G_{1}$ arrest was found in NGX6 expressing cells in our studies.

NGX6 activates Smad4-dependent signaling. To confirm activation of Smad4 following exogenous expression of NGX6 in T1-tam cells, we performed western blot analysis using antibodies that recognize phosphorylated, active Smad family members. Western blot analysis showed that phosphorylated levels of Smad2/3 significantly increased in T1-tam cells compared to T1 cells. Total protein levels of $\mathrm{Smad} 2 / 3$ remained unchanged (Fig. 5). In contrast, the total protein level of Smad4 significantly increased in T1-tam cells (Fig. 5). Upregulation of p21 and downregulation of cyclin D1 were found accompanied with activation of Smad4. After Smad2/3 target siRNA treatment, both the proteins of the Smad signaling pathway (Fig. 5) and the viability and apoptosis of T1 cells showed no changes (Fig. 3). These results indicated that Smad2/3 knockdown $\mathrm{T} 1$ cells showed no reaction to tamoxifen. The changes of all above proteins in $\mathrm{T} 2$ and $\mathrm{T} 3$ clones were similar to the T1 clone (Fig. 5).

\section{Discussion}

In an attempt to provide a novel biotherapy to tamoxifenresistant breast tumors, we carried out this study. A number of independent studies have evaluated the expression levels of NGX6 gene in various malignancies (26-28). Eskandari-Nasab et al (29) found that the relative level of NGX6 mRNA was significantly lower in cancer than that in non-cancer breast tissue specimens by real-time PCR. Consistent with previous studies, we found the levels of NGX6 mRNA and protein in breast cancer tissues were lower than in normal tissue. Interesting, NGX6 expressed at lower level in cancer tissues from tamoxifen-resistant patients than tamoxifen-sensitive 

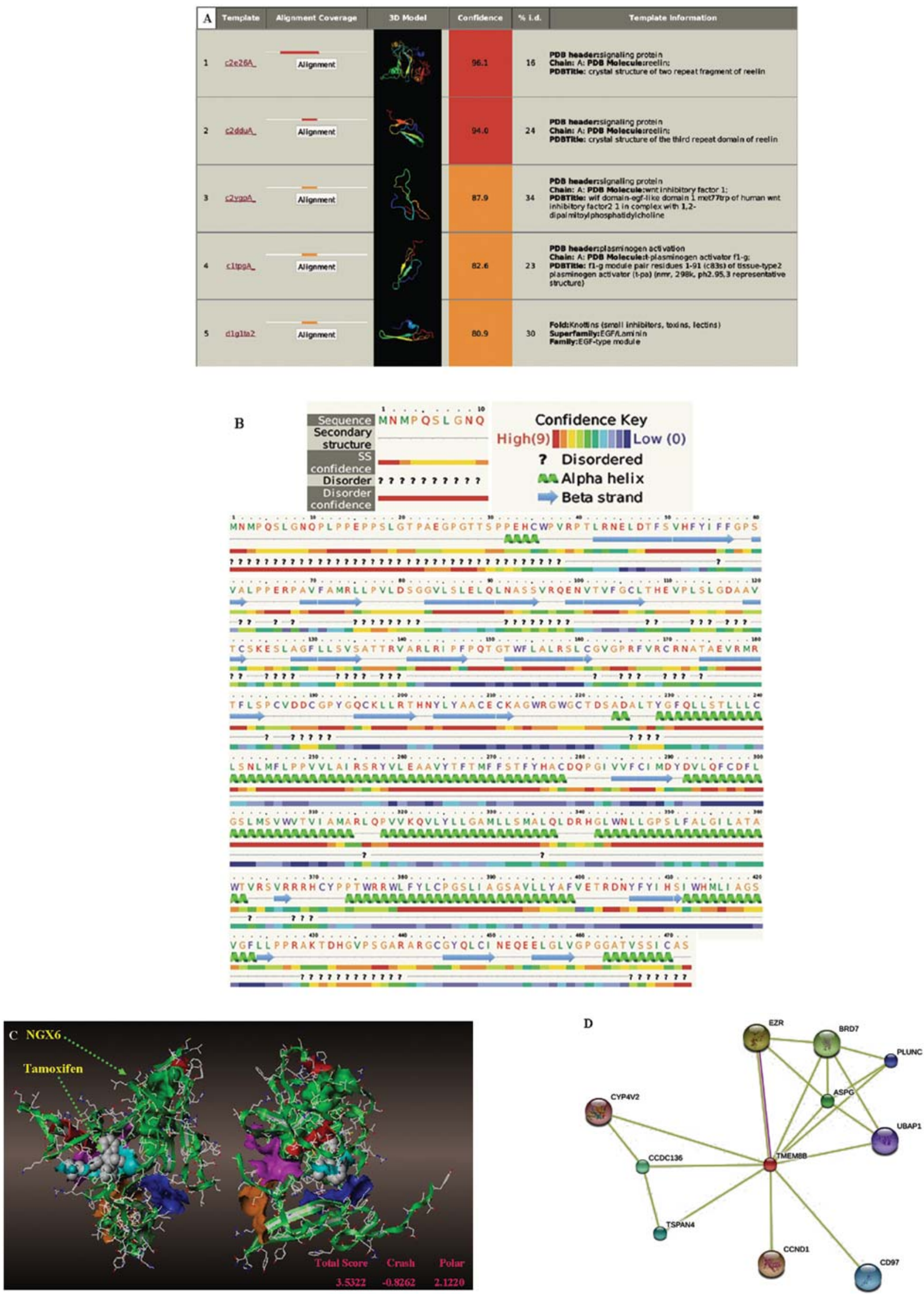

Figure 4. Predicted mechanism(s) of NGX6 expression improves the sensitivity of TRM-7 cells to tamoxifen. (A) Cropped view of the top five hits in the primary table of the fold recognition results, including images of the protein models produced and descriptors of the fold and superfamily of the template used. (B) The secondary structure and disorder predictions of NGX6 protein. The two-dimensional structure was predicted at Protein Homology/analogY Recognition Engine (PHYRE) from the Structural Bioinformatics Group. (C) Prediction of the docking between NGX6 protein and tamoxifen by SYBYL-X 1.3. The three-dimensional structure was of NGX6 protein predicated by PHYRE 2.0 and generated by Modeler. Structure of tamoxifen (CID_2733526) was downloaded from Pubchem Compound (http://www.ncbi.nlm.nih.gov/pccompound). (D) A graph showing the proteins associated with NGX6 protein was provided by STRING database. 


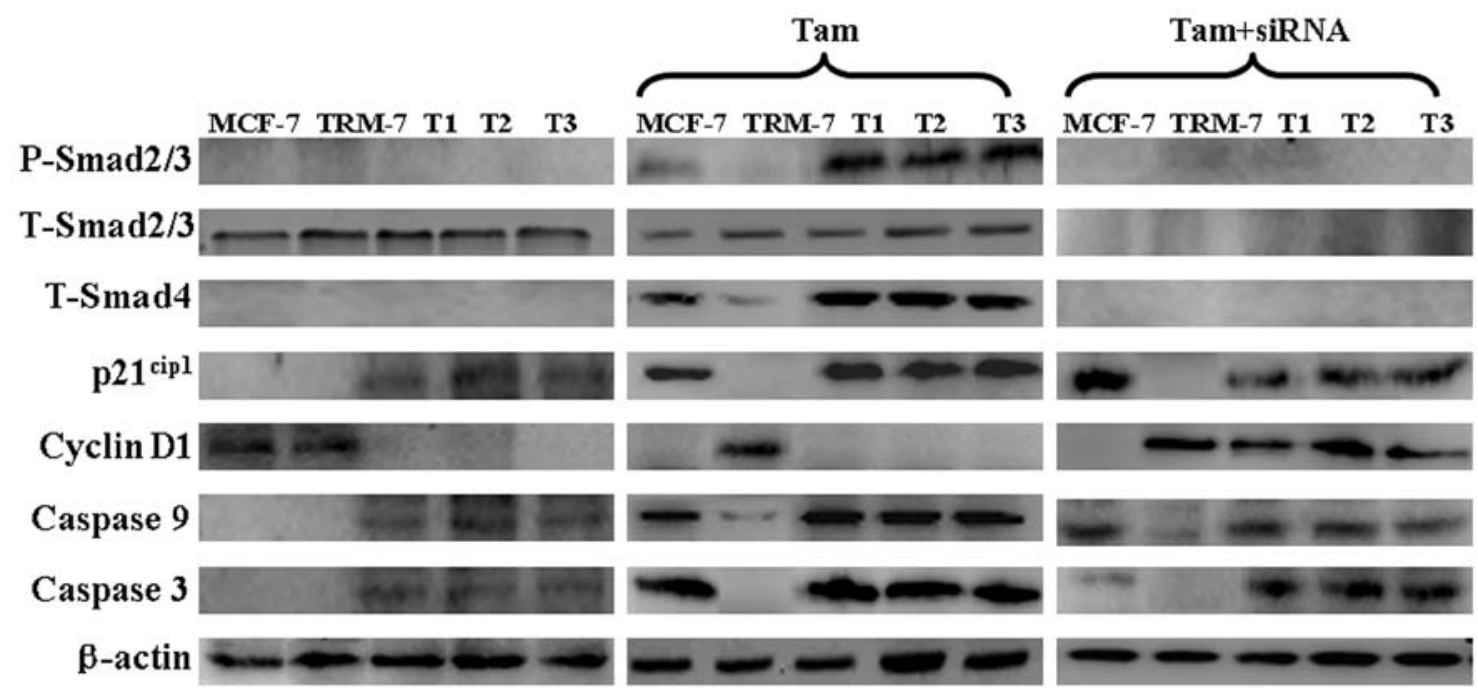

Figure 5. NGX6 regulates Smad family members in treated TRM-7 cells. Western blot analysis was performed using T-Smad2/3 and P-Smad2/3, T-Smad4, Smad4, p2 $1^{\text {cipl } 1}$, cyclin D1, caspase-9 and -3. Each experiment was performed in triplicate. Tam, tamoxifen; siRNA, Smad2/3-targeted siRNA.

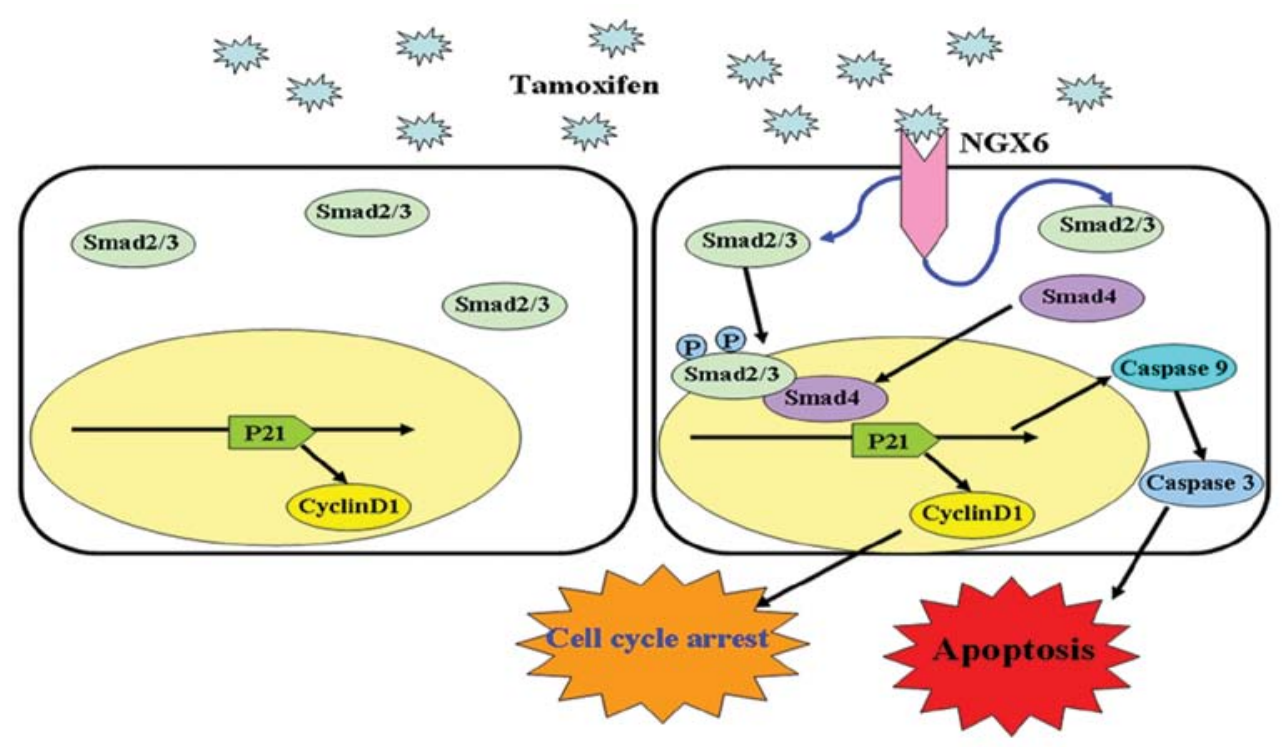

Figure 6. A proposed model for NGX6 expression improves the sensitivity of tamoxifen-resistant MCF-7 cells through modulation of Smad signaling pathway.

patients. Based on this result, we predicted that NGX6 may affect the sensitivity of breast cancer to tamoxifen. So we upregulated NGX6 expression in tamoxifen-resistant breast cancer cells TRM-7 and detected the antitumor activities of NGX6. We confirmed that NGX6 could inhibit viability, induce cell cycle arrest and apoptosis. Previous studies have showed that NGX6 inhibits proliferation (9) and arrests cell cycle progression at $\mathrm{G}_{0} / \mathrm{G}_{1}$ phase of colon cancer cells in vitro (30). However, the main purpose of our study was to identify whether NGX6 could improve the sensitivity of tamoxifenresistant breast cancer cells. Furthermore, we confirmed a higher apoptotic ratio in NGX6-expressing breast cancer cells after tamoxifen treatment. The results indicated NGX6 may be as a receptor to tamoxifen. In other words, tamoxifen may play its function through NGX6. Interesting, we found tamoxifen could dock into the active centers of NGX6 by using computer simulation tool. Guo et al (31) found that indomethacin and
NGX6 inhibit the proliferation and invasiveness of HT-29 and SW620 colon cancer cells by attenuating the WNT/ $\beta$-catenin signaling pathway. Overexpression of NGX6 led to the inhibition of nuclear translocation of JNK1/2 proteins and caused the accumulation of p-JNK1 protein in cytoplasm (32). However, the mechanism of NGX6 in breast cancer cells is not clear. We predicted the potential signaling pathway of NGX6 by using STRING database. According to both the simulation and the experimental results, we performed a preliminary screen of signaling pathways that have tumor suppressor function and are not confirmed by previous studies to determine which pathways are affected by NGX6 expression in TRM-7 cells. We found that of all the pathways that we screened, only Smad4-dependent signaling changed with the combination of NGX6 and tamoxifen. Interesting, we identified that NGX6 and tamoxifen activated downstream proteins in the Smad signaling pathway. In addition, the results were confirmed 
by using Smad2/3 siRNA. The Smad family of proteins are classified according to their different functions; Smad2 and -3 are the 'receptor-regulated SMADs', Smad4 is termed the 'common-mediator SMAD' (33). Phosphorylated Smad2/3 form complexes with Smad4, translocate to the nucleus and regulate the transcription of target genes by direct binding to specific DNA sequences (34). We also confirmed the levels of $\mathrm{p}-\mathrm{Smad} 2 / 3$ and Smad4 were significantly increased after NGX6 and tamoxifen treatment. The effects were reversed by Smad2/3 siRNA. Consistent with the results of cell experiments, knockdown of Smad2/3 expression by RNAi could also reduce the antitumor activities of NGX6 and tamoxifen.

In conclusion, our data showed the distinct content of NGX6 in tamoxifen-resistant and tamoxifen-sensitive patients. NGX6 may play a role in inhibiting proliferation, inducing apoptosis and arresting cell cycle of breast cancer cells. However, in combination with tamoxifen, the effects of NGX6 were significantly strengthened. Tamoxifen could dock into the active centers of NGX6. Furthermore, we confirmed NGX6 and tamoxifen activated the Smad signaling pathway (Fig. 6). These data provide experimental basis for biotherapy of tamoxifen-resistant breast cancer.

\section{Acknowledgements}

The authors wish to thank Miss Yu Miao for technical support.

\section{References}

1. Zainuddin $\mathrm{N}$, Jaafart $\mathrm{H}$, Isa MN, et al: Loss of heterozygosity on chromosomes $10 \mathrm{q}, 9 \mathrm{p}, 17 \mathrm{p}$ and $13 \mathrm{q}$ in malays with malignant glioma. Neurol Res 26: 88-92, 2004.

2. Nishisaka T, Takeshima $Y$ and Inai K: Evaluation of p53 gene mutation and loss of heterozygosity of $3 p, 9 p$ and $17 p$ in precancerous lesions of 29 lung cancer patients. Hiroshima J Med Sci 49: 109-116, 2000.

3. Wistuba II, Behrens C, Milchgrub S, et al: Sequential molecular abnormalities are involved in the multistage development of squamous cell lung carcinoma. Oncogene 18: 643-650, 1999.

4. Perinchery G, Bukurov N, Nakajima K, et al: High frequency of deletion on chromosome $9 \mathrm{p} 21$ may harbor several tumorsuppressor genes in human prostate cancer. Int $\mathbf{J}$ Cancer 83: 610-614, 1999.

5. Partridge M, Emilion G, Pateromichelakis S, et al: Location of candidate tumour suppressor gene loci at chromosomes $3 \mathrm{p}$, $8 \mathrm{p}$ and $9 \mathrm{p}$ for oral squamous cell carcinomas. Int J Cancer 83 . 318-325, 1999.

6. Calin GA, Dumitru CD, Shimizu M, et al: Frequent deletions and down-regulation of micro-RNA genes miR15 and miR16 at $13 q 14$ in chronic lymphocytic leukemia. Proc Natl Acad Sci USA 99: 15524-15529, 2002.

7. Peng S, Fan S, Li X, et al: The expression of ezrin in NPC and its interaction with NGX6, a novel candidate suppressor. Cancer Sci 8: 341-349, 2007.

8. Ma J, Zhou J, Fan S, et al: Role of a novel EGF-like domaincontaining gene NGX6 in cell adhesion modulation in nasopharyngeal carcinoma cells. Carcinogenesis 26: 281-291, 2005.

9. Wang L, Ma J, Li J, et al: NGX6 gene inhibits cell proliferation and plays a negative role in EGFR pathway in nasopharyngeal carcinoma cells. J Cell Biochem 95: 64-73,2005.

10. Jemal A, Bray F, Center MM, et al: Global cancer statistics. CA Cancer J Clin 6: 69-90, 2011.

11. Xiong J, Yu D, Wei N, et al: An estrogen receptor alpha suppressor, microRNA-22, is downregulated in estrogen receptor alpha-positive human breast cancer cell lines and clinical samples. FEBS J 277: 1684-1694, 2010.
12. Hu Y, Fan L, Zheng J, et al: Detection of circulating tumor cells in breast cancer patients utilizing multiparameter flow cytometry and assessment of the prognosis of patients in different CTCs levels. Cytometry A 77: 213-219, 2010.

13. Zhou FF, Xia LP, Wang X, et al: Analysis of prognostic factors in male breast cancer: a report of 72 cases from a single institution. Chin J Cancer 29: 184-188, 2010.

14. Arpino G, De Angelis C, Giuliano M, et al: Molecular mechanism and clinical implications of endocrine therapy resistance in breast cancer. Oncology 77 (Suppl 1): 23-37, 2009.

15. Henry NL and Hayes DF: Can biology trump anatomy? Do all node-positive patients with breast cancer need chemotherapy? J Clin Oncol 25: 2501-2503, 2007.

16. Jaiyesimi IA, Buzdar AU, Decker DA, et al: Use of tamoxifen for breast cancer: twenty-eight years later. J Clin Oncol 13: 513-529, 1995.

17. Kim MR, Choi HK, Cho KB, et al: Involvement of Pin1 induction in epithelial-mesenchymal transition of tamoxifen-resistant breast cancer cells. Cancer Sci 100: 1834-1841, 2009.

18. Livak KJ and Schmittgen TD: Analysis of relative gene expression data using real-time quantitative PCR and the 2(-Delta Delta C(T)) method. Methods 25: 402-408, 2001.

19. Markaryan A, Nelson EG, Tretiakova M, et al: Technical report: immunofluorescence and TUNEL staining of celloidin embedded human temporal bone tissues. Hear Res 241: 1-6, 2008.

20. Hurst PR, Mora JM and Fenwick MA: Caspase-3, TUNEL and ultrastructural studies of small follicles in adult human ovarian biopsies. Hum Reprod 21: 1974-1980, 2006.

21. Bennett-Lovsey RM, Herbert AD, Sternberg MJ, et al: Exploring the extremes of sequence/structure space with ensemble fold recognition in the program Phyre. Proteins 70: 611-625, 2008.

22. Kelley LA and Sternberg MJ: Protein structure prediction on the Web: a case study using the Phyre server. Nat Protoc 4: 363-371, 2009.

23. Martí-Renom MA, Stuart AC, Fiser A, et al: Comparative protein structure modeling of genes and genomes. Annu Rev Biophys Biomol Struct 29: 291-325, 2000.

24. Szklarczyk D, Franceschini A, Kuhn M, et al: The STRING database in 2011: functional interaction networks of proteins, globally integrated and scored. Nucleic Acids Res 39 (Database issue): D561-D568, 2011.

25. D'Arcangelo G, Miao GG, Chen SC, et al: A protein related to extracellular matrix proteins deleted in the mouse mutant reeler. Nature 374: 719-723, 1995.

26. Wang L, Xiang B, Yi M, et al: Identification of a new seven-span transmembrane protein: NGX6a is downregulated in nasopharyngeal carcinoma and is associated with tumor metastasis. J Histochem Cytochem 58: 41-51, 2010.

27. Guo Q, Shen S, Liao M, et al: NGX6 inhibits cell invasion and adhesion through suppression of Wnt/betacatenin signal pathway in colon cancer. Acta Biochim Biophys Sin 42: 450-456, 2010.

28. Xiao JD and Shen SR: Expression and significance of NGX6 gene in human hepatocellular carcinoma. Zhong Nan Da Xue Xue Bao Yi Xue Ban 33: 937-941, 2008.

29. Eskandari-Nasab E, Hashemi M, Rezaei H, et al: Evaluation of UDP-glucuronosyltransferase 2B17 (UGT2B17) and dihydrofolate reductase (DHFR) genes deletion and the expression level of NGX6 mRNA in breast cancer. Mol Biol Rep 39: 10531-10539, 2012.

30. Wang XY, Wu MH, Liu F, et al: Differential miRNA expression and their target genes between NGX6-positive and negative colon cancer cells. Mol Cell Biochem 345: 283-290, 2010.

31. Guo Q, Wu M, Lian P, et al: Synergistic effect of indomethacin and NGX6 on proliferation and invasion by human colorectal cancer cells through modulation of the Wnt/beta-catenin signaling pathway. Mol Cell Biochem 330: 71-81, 2009.

32. Peng Y, Li H, Wu M, et al: NGX6 inhibits AP-1 and Ets-1 expression and down-regulates cyclin D1 in human colorectal cancer. Acta Biochim Biophys Sin 41: 504-514, 2009.

33. Schmierer B and Hill CS: TGFbeta-SMAD signal transduction: molecular specificity and functional flexibility. Nat Rev Mol Cell Biol 8: 970-982, 2007.

34. Jacob D, Davis J, Zhu H, et al: Suppressing orthotopic pancreatic tumor growth with a fiber-modified adenovector expressing the TRAIL gene from the human telomerase reverse transcriptase promoter. Clin Cancer Res 10: 3535-3541, 2004. 